\title{
Electrochemical Investigation of Acetaminophen with a Carbon Nano-tube Composite Film Electrode
}

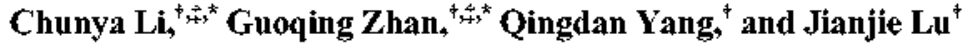 \\ "College of Chemistry and Materials Science, South-Central University for Nationalities, Wuhan 430074, China \\ "E-mail: lichychem@163.com \\ ${ }^{\star}$ Key Laboratory of Analytical Chemistry of the State Ethnic Affairs Commission, Wuthan 430074, China \\ Received July 30,2006
}

\begin{abstract}
Electrochemical behaviors of acetaminophen at a muti-wall carbon nano-tube composite fillm modified glassy carbon electrode were investigated by cyclic voltammetry, linear sweep voltammetry and chronocoulometry. Compared with that obtained at the unmodified electrode, the peak currents were enhanced significantly, and the oxidation peak shifted towards more negative potential with the reduction peak shifted positively. The peakto-peak separation turned narrow, and suggested that the reversibility was improved greatly. Experimental parameters, such as scan rate, pII and accumulation conditions were optimized. It was found that a maximum current response can be obtained at $\mathrm{pII}=5.0$ after accumulation at $-0.50 \mathrm{~V}$ for $80 \mathrm{~s}$. The oxidation peak current was found to be linearly related to acetaminophen concentration over the range of $5.0 \times 10^{-7} \sim 1.0 \times 10^{-4} \mathrm{~mol}$ $\mathrm{L}^{-1}$ with a detection limit of $5.0 \times 10^{-8} \mathrm{~mol} \mathrm{~L}-1 . \Lambda$ convenient and sensitive electrochemical method was developed for the determination of acetaminophen in a commercial paracetamol oral solution. Its practical application demonstrated that it has good selectivity and high sensitivity.
\end{abstract}

Key Words : Acetaminophen, Multi-wall carbon nano-tube, Electroanalysis

\section{Introduction}

Acetaminophen, $N$-acetyl-p-aminophenol, is important and extensively used as an altemative to aspirin without the secondary effects of the salicylates on the gastric mucosa.' In proper therapeutic dose, $<1$ g/time (or $<2$ g/day), acetaminophen is readily metabolized and is safe to patients with sensitivity to aspirine, therefore, is often self-prescribed without medical control, to alleviate moderate pain, to calm fever, lumbar pain, migraine or nonspecific indications. Most references state that the maximum daily dose of acetaminophen is $4 \mathrm{~g}$. Patients taking more than this amount, especially those with certain risk factors, are more likely to develop toxicity. Recent studies have shown that overdose of acetaminophen is associated to hepatic toxicity and renal failure despite of its apparent innocuous character ${ }^{2.3}$ It is therefore important to develop an analytical technique to determine acetaminophen accurately.

To date, numerous methods have been proposed for analysis of acetaminophen in pharmaceutical preparations, such as titrimetric analysis, ${ }^{4}$ spectrophotometry, ${ }^{5-10}$ spectrofluorometry," high performance liquid chromatography, ${ }^{12,13}$ capillary electrophoresis, ${ }^{14.15}$ flow injection analysis ${ }^{16,17}$ and electroanalysis. ${ }^{18-22}$ Spectrophotometric methods usually require sample pre-treatments (e.g. extraction, complex formation, etc.) which can be laborious and time consuming. Compared with other techniques, voltammetric techniques are more selective, less time-consuming and widely used for the determination of acetaminophen. A relatively simple and rapid electrochemical method for the detection of acetaminophen in $1.0 \mathrm{~mol} \mathrm{~L}^{-1} \mathrm{HCl}$ solution was developed with glassy carbon electrode. ${ }^{18}$ Chemically modified electrodes have also attracted attentions, C-60-modified glassy carbon electrode, ${ }^{19}$ boron-doped diamond thin film electrode, ${ }^{20}$ nanogold modified indium tin oxide electrode ${ }^{21}$ and a $\mathrm{Cu}$ (II)-conducting polymer complex modified electrode ${ }^{22}$ have been constructed for the determination of acetaminophen in pharmaceutical and medical applications.

The present work reports the electrochemical behaviors of acetaminophen at a multi-wall carbon nano-tube/dihexadecyl hydrogen phosphate/polyethylene glycol composite film modified glassy carbon electrode. The negative shift of the oxidation peak potential and the great enhancement of the oxidation peak current reveal that the film has a strong catalytic function towards the oxidation of acetaminophen, due to the unusual properties of carbon nano-tube such as strong adsorptive ability, huge specific area, subtle electronic properties as well as excellent electrocatalytic activity. Based on the sensitive current response, a simple and convenient method is developed for the determination of acetaminophen. The specific features of this method are shown in Table 1 and compared with other electrochemical methods. Its successful application to quantify the content of acetaminophen in commercial pharmaceutical preparations demonstrates that the film electrode has potential in practical use.

\section{Experimental Section}

Apparatus. All electrochemical experiments were carried out on a CHI-660A electrochemical workstation $(\mathrm{CH}$ Instrument Inc., USA) with a conventional three-electrode system including the multi-wall carbon nano-tube composite film modified glassy carbon electrode as working electrode, 
Table 1. Comparison of electroanalytical data for acetaninophen deternination

\begin{tabular}{|c|c|c|c|c|}
\hline Electrode & Analytical range & Limits of detection & Accumulation time & reference \\
\hline This method & $5.0 \times 10^{-7}-1.0 \times 10^{-4} \mathrm{~mol} \mathrm{~L}^{-1}$ & $5.0 \times 10^{-8} \mathrm{~mol} \mathrm{~L}^{-1}$ & $80 \mathrm{~s}$ & \\
\hline glassy carbon electrode & $6.6 \times 10^{-6}-1.3 \times 10^{-4} \mathrm{~mol} \mathrm{~L}^{-1}$ & & $60 \mathrm{~s}$ & [18] \\
\hline C-60-modified electrode & $0.05 \sim 1.5 \mathrm{mmol} \mathrm{L}-1$ & $0.05 \mathrm{mmol} \mathrm{L}^{-1}$ & & [19] \\
\hline boron-doped diamond electrode & $0.1-8.0 \mathrm{mmol} \mathrm{L}^{-1}$ & 10 fanol L $\mathrm{L}^{-1}$ & & [20] \\
\hline nanogold modified indium tin oxide electrode & $2.0 \times 10^{7}-1.5 \times 10^{3} \mathrm{~mol} \mathrm{~L}^{-1}$ & $1.8 \times 10^{7} \mathrm{~mol} \mathrm{~L}^{-1}$ & & [21] \\
\hline $\begin{array}{l}\text { Cur(II-conducting polymer complex modified } \\
\text { electrode }\end{array}$ & $2.0 \times 10^{5}-5.0 \times 10^{3} \mathrm{~mol} \mathrm{~L}-1$ & $5.0 \times 10^{6} \mathrm{~mol} \mathrm{~L}^{-1}$ & & [22] \\
\hline Glassy carbon electrode & $0.09 \sim 0.93 \mathrm{mg} \mathrm{L}^{-1}$ & & $160 \mathrm{~s}$ & [26] \\
\hline
\end{tabular}

a platinum wire counter electrode and a saturated calomel reference electrode, respectively. Scanning electron micrograph was done with a Hitachi X-650 microscope. Ultraviolet (UV) detection was carried out at a Lambda $35 \mathrm{UV}$ spectroscopy (Perkin Elemer, USA)

Reagents. Acetaminophen was obtained from Study Center of National Standard Substance (Beijing, China). Stock standard solution of acetaminophen was prepared from ethanol and stored in a refrigerator until used. An aqueous solution was prepared daily by simple dilution of the stock solution with phosphate buffer. Dihexadecyl hydrogen phosphate (DHP) was bought from Fluka (Switzerland). Polyethylene glycol 10000 (PEG) were purchased from Shanghai Regents Co. (Shanghai, China). Phosphate buffer (PB) was prepared from $1 / 15 \mathrm{~mol} \mathrm{~L}^{-1}$ $\mathrm{KH}_{2} \mathrm{PO}_{4}$ and $1 / 15 \mathrm{~mol} \mathrm{~L} \mathrm{~L}^{-1} \mathrm{Na}_{2} \mathrm{HPO}_{4}$, its $\mathrm{pH}$ value was adjusted with $\mathrm{H}_{3} \mathrm{PO}_{4}$. The multi-wall carbon nano-tube, obtained from Central China Normal University, was synthesized by a catalytic pyrolysis method. Before use, multi-wal] carbon nano-tubes were purified by refluxing in $\mathrm{H}_{2} \mathrm{SO}_{4}$ $\mathrm{HNO}_{3}$ system $(\mathrm{v} / \mathrm{v}=3: \mathrm{l})$ at $120^{\circ} \mathrm{C}$ for $12 \mathrm{~h}$, and then was washed with distilled water thoroughly. Other chemicals used were of analytical grade, and all compounds were used without further purification. All solutions were prepared with redistilled water.

Preparation of the MWNT/DHP/PEG composite film electrode. A glassy carbon electrode (3 $\mathrm{mm}$ in diameter) was polished to a mirror finished with polish paper and $0.3-$ $0.05 \mu \mathrm{m}$ alumina slurry, and cleaned thoroughly in an ultrasonic cleaner with $1: 1$ nitric acid solution, alcohol, and redistilled water, sequentially.

$1.0 \mathrm{mg}$ dihexadecyl hydrogen phosphate and $2.0 \mathrm{mg}$ Polyethylene glycol 10000 were dissolved into $1 \mathrm{~mL}$ redistilled water. Then, $1.0 \mathrm{mg}$ purified multi-wall carbon nano-tube was added. A homogeneous and stable suspension of MWNT/DHP/PEG was achieved with the aid of ultrasonication agitation for about $30 \mathrm{~min}$. The suspension was cast on the electrode surface and dried under infrared lamp. The obtained MWNT/DHP/PEG composite film electrode was characterized by scanning electron micrograph. The surface morphology of the composite film electrode was shown in Figure I. It can be seen obviously that many carbon nano-tubes are fixed on the glassy carbon electrode surface. The freshly prepared composite film electrodes were activated in $\mathrm{PB}$ solution by successive cyclic

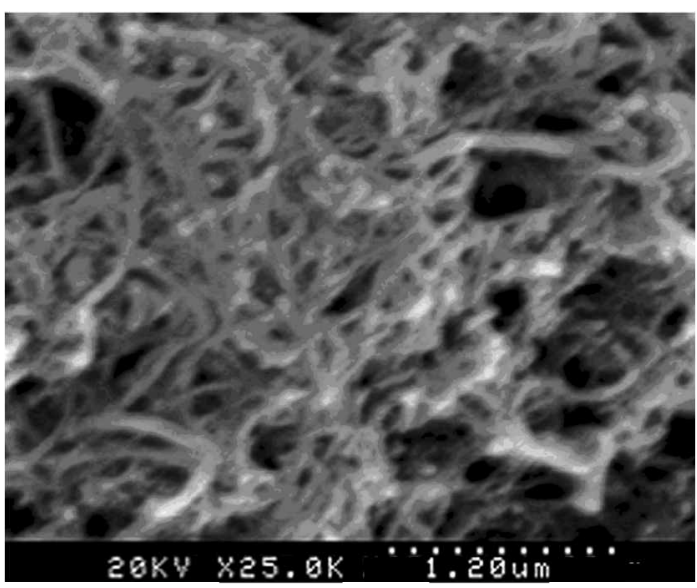

Figure 1. Scanning clectronic microscopy image of MWNT/DHP/ PEG composite film electrode.

scans from $-0.20 \mathrm{~V}$ to $1.00 \mathrm{~V}$ until the stable voltammograms were obtained. A similar procedure was applied for the dihexadecyl hydrogen phosphate film electrode preparation without multi-wall carbon nano-tube and Polyethylene glycol 10000 .

Electrochemical measurements. Voltammetric determination of acetaminophen was carried out in a voltammetric cell with $10 \mathrm{~mL}$ of supporting electrolyte solution. The accumulation step was performed at $-0.50 \mathrm{~V}$ for $80 \mathrm{~s}$ with stirring, and voltammograms were recorded from $-0.20 \mathrm{~V}$ to $1.00 \mathrm{~V}$ after $10 \mathrm{~s}$ quiescence. The oxidation peak current measured at $0.40 \mathrm{~V}$ was applied for the quantification of acetaminophen. After each measurement, in order to remove the previous deposits completely, the modified electrode surface was refreshed by successive cyclic voltammetric sweeps in a blank electrolyte solution to produce a reproducible electrode surface. The same procedure was applied in the samples analysis. All electrochemical experiments were carried out at room temperature $\left(25 \pm 2{ }^{\circ} \mathrm{C}\right)$. Removal of oxygen was achieved by using high purity $\mathrm{N}_{2}$.

\section{Results and Discussion}

Voltammetric behaviors of acetaminophen. Cyclic voltammetry was applied for the electrochemical investigation of $1.0 \times 10^{-5}$ mol $\mathrm{L}^{-1}$ acetaminophen at the film electrodes in phosphate buffer $(\mathrm{pH}=5.0)$. As shown in 


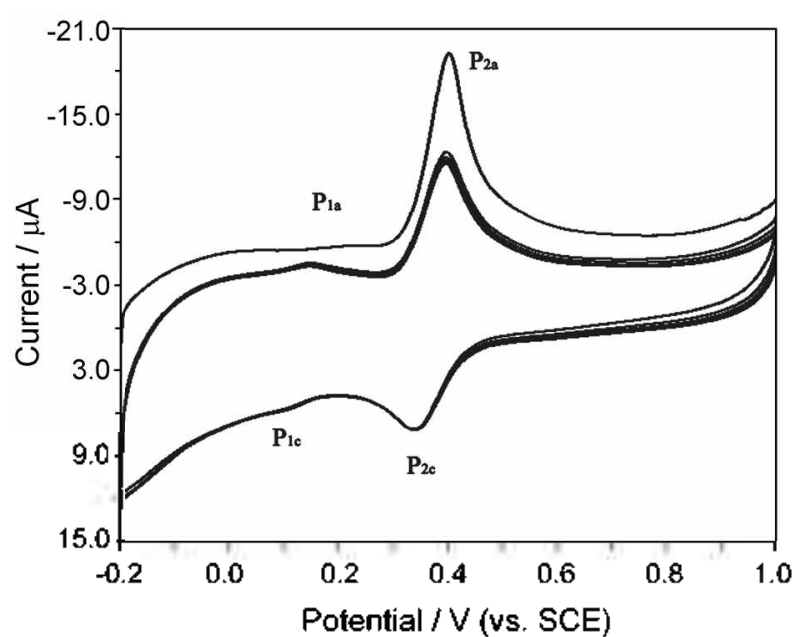

Figure 2. Cyclic voltammograms of $1.0 \times 10^{-5} \mathrm{~mol} \mathrm{L^{-1 }}$ acetaminophen at the MWNT/DHP/PEG composite film electrode in phosphate buffer $(\mathrm{pH}=5.0)$. Scan rate: $100 \mathrm{mVs}^{-1}$.

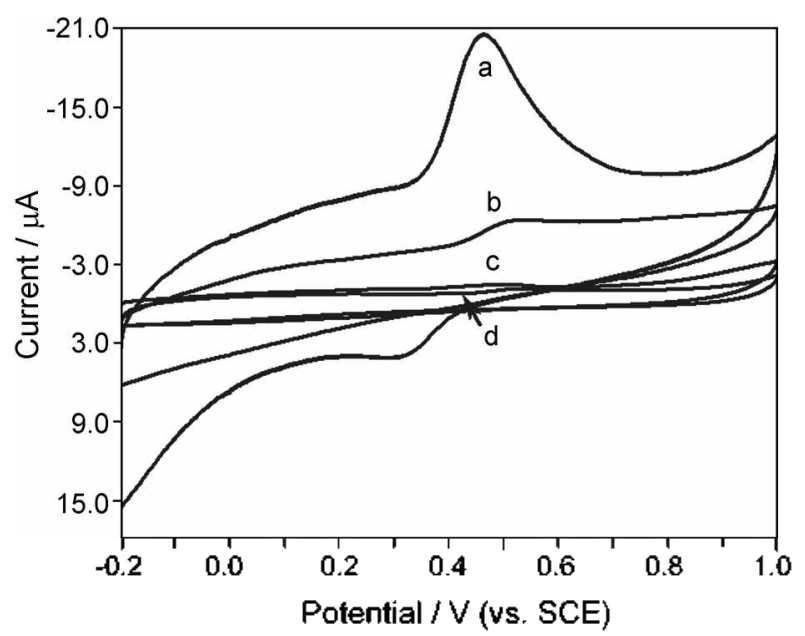

Figure 3. Voltanmograms of $1.0 \times 10^{-5} \mathrm{~mol} \mathrm{~L}^{-1}$ acetauninophen at (a) the MWNT/DHP/PEG conposite film elcetrode; (b) the DHP/ PEG film electrode; (c) the unmodified electrode and (d) the DHP film electrode in phosphate buffer $(\mathrm{pH}=5.0)$. Scan rate: 100 $\mathrm{mVs}^{-1}$.

Figure 2, a pair of redox peaks $\left(\mathrm{P}_{2 a}\right.$ and $\left.\mathrm{P}_{2 c}\right)$ can be observed at the composite film electrode. Another pair of peaks ( $\mathrm{P}_{\mathrm{I}}$ and $\mathrm{P}_{\mathrm{Ic}}$ ) should be corresponds to the redox of carbon nanotubes. Voltammetric behaviors of acetaminophen at different electrodes were also investigated, and voltammograms were shown in Figure 3. A weak irreversible oxidation peak located at $0.535 \mathrm{~V}$ can be seen at the unmodified electrode. When a dihexadecyl hydrogen phosphate film modified electrode was used, although the oxidation peak potential shifted negatively to $0.495 \mathrm{~V}$, the peak current decreased conversely (curve d). It's mainly due to that dihexadecyl hydrogen phosphate can form a perfect thin film on the electrode surface, and thus blocks the mass transportation and electron transfer of acetaminophen. Moreover, a significant current increase at the DHP/PEG film electrode can be observed (curve b), and the peak potential negatively shifted

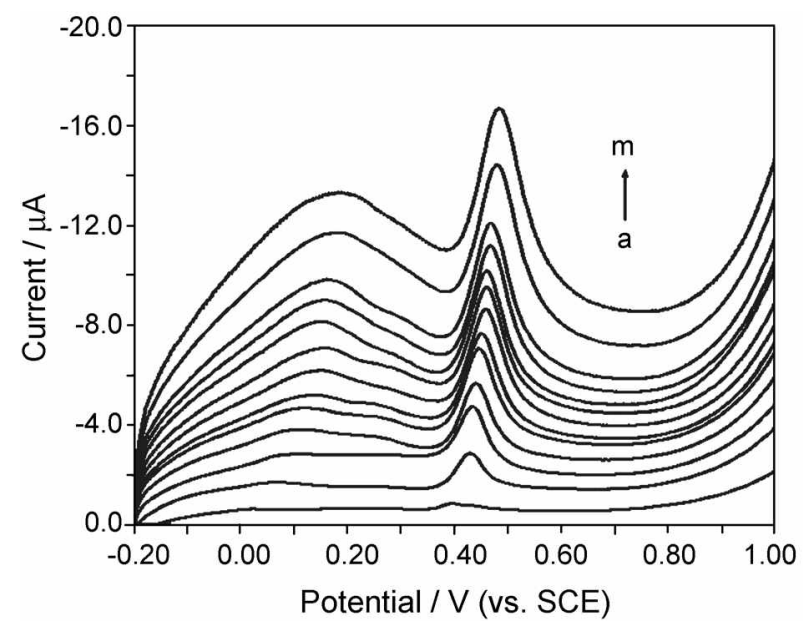

Figure 4. Linear sweep voltammograms for $1.0 \times 10^{-5} \mathrm{~mol} \mathrm{~L}^{-1}$ acetarninophen at different scan rate (from a to $\mathrm{m}$ ): $10,30,50,70$, $90,100,120,140,160,180,200,250,300 \mathrm{mV} \mathrm{s}^{-1}$. Supporting electrolyte: $1 / 15 \mathrm{~mol} \mathrm{~L}-1$ phosphate buffer $(\mathrm{pH}=5.0)$.

to $0.520 \mathrm{~V}$ meaning that the film can facilitate the electrochemical oxidation of acetaminophen. The MWNT/DHP/ PEG film modified electrode was employed for comparison, a sensitive oxidation peak was observed at $0.464 \mathrm{~V}$ (curve a). In the reverse scan, a reduction peak located at $0.311 \mathrm{~V}$ was seen obviously, and the peak-to-peak separation tums narrow. The remarkable peak current enhancement and the decrease of oxidation overpotential undoubtedly verified that carbon nano-tube is an effective electrocatalyst for the electrochemical reaction of acetaminophen. The great improvement of the sensitivity in the determination of acetaminophen was on account of the unusual structure and properties of multi-wall carbon nano-tube, such as very large specific area, strong adsorptive ability and subtle electronic properties.

Effects of scan rate. Effects of scan rate on the oxidation of acetaminophen were investigated by linear sweep voltammetry in the range from $10 \mathrm{mVs}^{-1}$ to $300 \mathrm{mVs}^{-1}$, and voltammograms were shown in Figure 4. The peak current increased with a positive shift in the peak potential when the scan rate increased. The detail description of the relationship between the peak current and the square root of the scan rate was given in Figure 5. The linear curve indicated that the electrochemical reaction is predominantly diffusion controlled in a confined thin film.

Chronocoulometry. Chronocoulometry, an electrochemical measuring technique used for electrochemical analysis or for the determination of the kinetics and mechanism, was applied to investigate the oxidation of acetaminophen. The chronocoulometric curves of acetaminophen at the MWNT/ DHP/PEG composite film electrode (a), the unmodified electrode (b) and the dihexadecyl hydrogen phosphate film electrode (c) were presented in Figure 6. The diffusion coefficient $D$ and $Q$ is of acetaminophen on the MWNT/ DHP/PEG composite film electrode can be calculated according to the formula given by Anson ${ }^{23}$ 


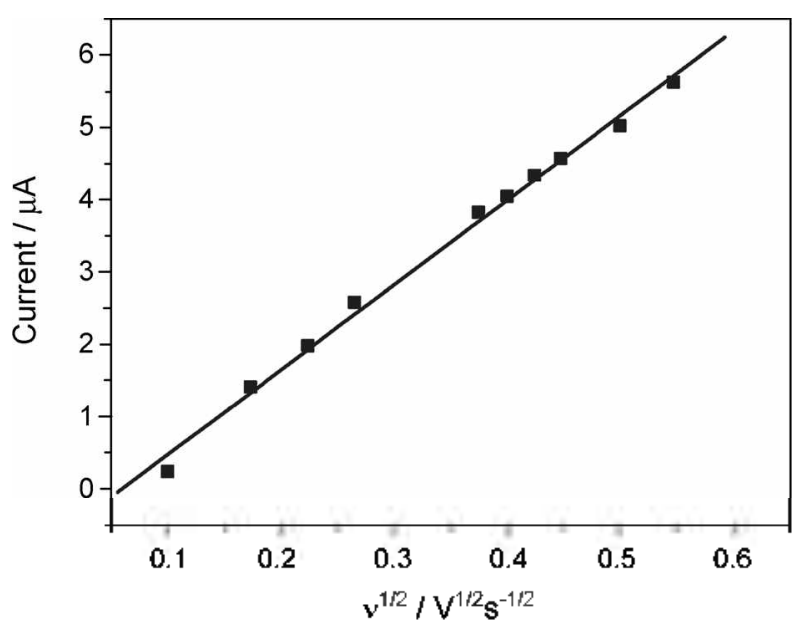

Figure 5. Dependence of the oxidation peak current on the scan rate.

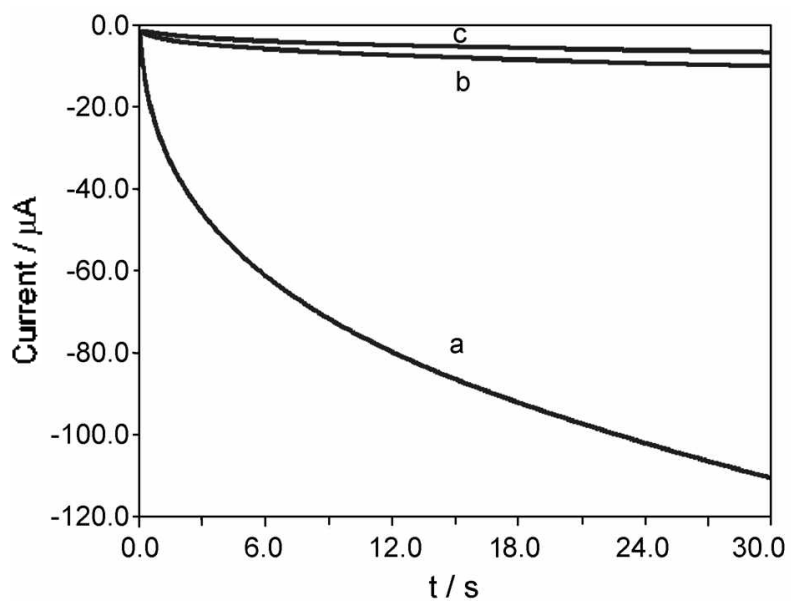

Figure 6. Chronocoulonetry of $1.0 \times 10^{-4} \mathrm{~mol} \mathrm{~L}^{-1}$ acetaminophen at the MWNT/DHP/PEG composite filtn electrode (a), the unmodified electrode (b) and the DHP film electrode(c). Initial potential $0.60 \mathrm{~V}$, final potential $1.00 \mathrm{~V}$, and pulse width $30 \mathrm{~s}$.

$$
Q=2 n F A C(D t)^{1 / 2} \pi^{-1 / 2}+Q_{\mathrm{dl}}+Q_{\mathrm{dds}}
$$

where $A$ is the area of the electrode, $C$ is the concentration of acetaminophen, $Q_{\text {III }}$ is double-layer charge, $Q_{\text {al }}$ the Faradaic charge due to the oxidation of adsorbed acetaminophen. Other symbols have their usual significance. $Q_{\mathrm{d} l}$ is assumed not changed in the current work. In this experiment, the plot of charge against $t^{1 / 2}$ shows a linear relationship. From the slope and intercept, the values of $D$ and $Q_{\text {ads }}$ can be obtained. The values of the slope and $Q_{\text {ads }}$ are $15.9 \mu \mathrm{C}$ and $24.1 \mu \mathrm{C}$ for the composite film electrode, $0.869 \mu \mathrm{C}$ and $1.82 \mu \mathrm{C}$ for the dihexadecyl hydrogen phosphate film electrode, $1.39 \mu \mathrm{C}$ and $2.48 \mu \mathrm{C}$ for the urmodified electrode. As the number of electrons involved in the oxidation of acetaminophen is 2 and $A=0.0707 \mathrm{~cm}^{2}$, $C=1.0 \times 10^{-4} \mathrm{~mol} \mathrm{~L}^{-1}$, it is calculated that $D=1.07 \times 10^{-4}$ $\mathrm{cm}^{2} \mathrm{~s}^{-1}$ at the composite film electrode, $3.19 \times 10^{-7} \mathrm{~cm}^{2} \mathrm{~s}^{-1}$ at the dihexadecyl hydrogen phosphate film electrode and $8.15 \times 10^{-7} \mathrm{~cm}^{2} \mathrm{~s}^{-1}$ at the unmodified electrode. The surface

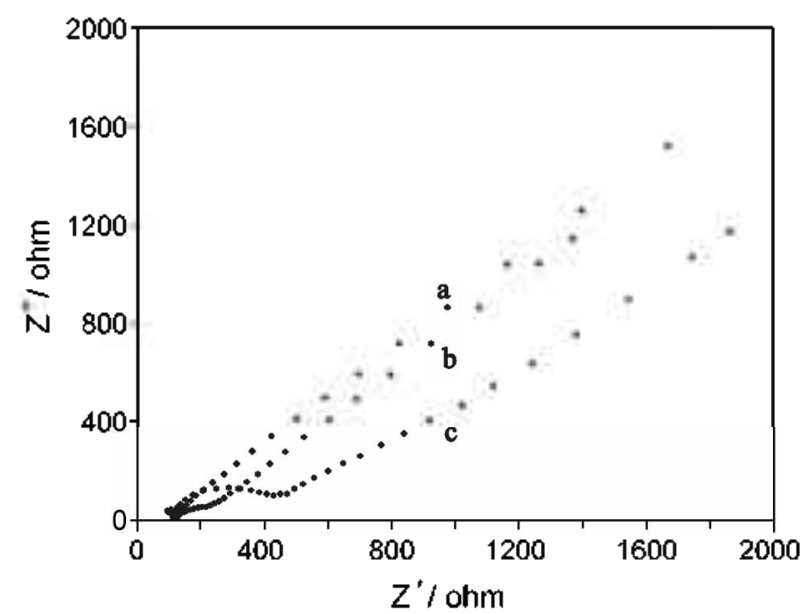

Figure 7. Nyquist diagram ( $Z^{\prime}$ vs. $Z^{\prime \prime}$ ) for the MWNT/DHP/PEG film electrode (a), the MWNT/DHP film electrode (b) and the unmodified electrode (c) in the presence of $10 \mathrm{mmol} \mathrm{L}^{-1}$ $\mathrm{K}_{3}\left[\mathrm{Fe}\left(\mathrm{CN}_{6}\right] / \mathrm{K}_{4}\left[\mathrm{Fe}(\mathrm{CN})_{6}\right](1: 1)\right.$-nixture. $0.2 \mathrm{~mol} \mathrm{~L}^{-1} \mathrm{KCl}$ was used as supporting clectrolyte.

concentration, $\Gamma_{\mathrm{s}}$, can be obtained by the following Equation: $\Gamma_{\mathrm{s}}=Q_{\text {axis }} / n F A$. At the composite film electrode, $\Gamma_{\mathrm{s}}$ is calculated as $1.77 \times 10^{-9} \mathrm{~mol} \mathrm{~cm}^{-2}$, however, it decrease to $1.33 \times 10^{-10} \mathrm{~mol} \mathrm{~cm}^{-2}$ at the dihexadecyl hydrogen phosphate film electrode and $1.82 \times 10^{-10} \mathrm{~mol} \mathrm{~cm}^{-2}$ at the unmodified electrode. It was undoubtedly that the presence of multi-wall carbon nano-tube can improve the adsorption of acetaminophen at the electrode surface so as to enhance the determination sensitivity significantly.

Electrochemical impedance spectroscopy. Electrochemical impedance spectroscopy is considered to be an effective tool for investigating the property of electrode interface ${ }^{24,25}$ Figure 7 shows the complex plane diagram (Nyquist plot, $Z$ ' versus $Z^{\prime \prime}$ ) for the electrochemical impedance spectroscopy of acetaminophen at the MWNT/DHP/PEG film electrode (a), the MWNT/DHP film electrode (b) and the unmodified electrode (c) in the presence of $10 \mu \mathrm{mol} \mathrm{L}^{-1} \mathrm{~K}_{3}\left[\mathrm{Fe}(\mathrm{CN})_{6}\right]$ $\mathrm{K}_{4}\left[\mathrm{Fe}(\mathrm{CN})_{6}\right](1: 1)$-mixture as redox probe and $0.2 \mathrm{~mol} \mathrm{~L}^{-1}$ $\mathrm{KCl}$ as supporting electrolyte. A semicircle with a large diameter is observed at the urmodified electrode, indicating a low charge transfer rate between acetaminophen and the electrode surface due to a biggish electron transfer resistance. However, the diameter of semicircle diminishes significantly in the presence of MWNT/DHP film. It was obvious that charge transfer resistance of the electrode surface decreased and the charge transfer rate sped up. In the case of the MWNT/DHP/PEG film electrode, no obvious semicircle was observed at the research frequency range. This suggested that the electron transfer resistance can be neglected and the electrochemical reaction has been facilitated greatly.

Influences of $\mathbf{p H}$ value. The influence of $\mathrm{pH}$ on the oxidation of acetaminophen at the composite film electrode was investigated in the $\mathrm{pH}$ range from 4.5 to 8.8 . The effect of $\mathrm{pH}$ on the oxidation peak current was shown in Figure 8, a maximum current response is obtained at $\mathrm{pH}=5.0$, and a decrease is observed with $\mathrm{pH}$ further increase. Therefore, the 


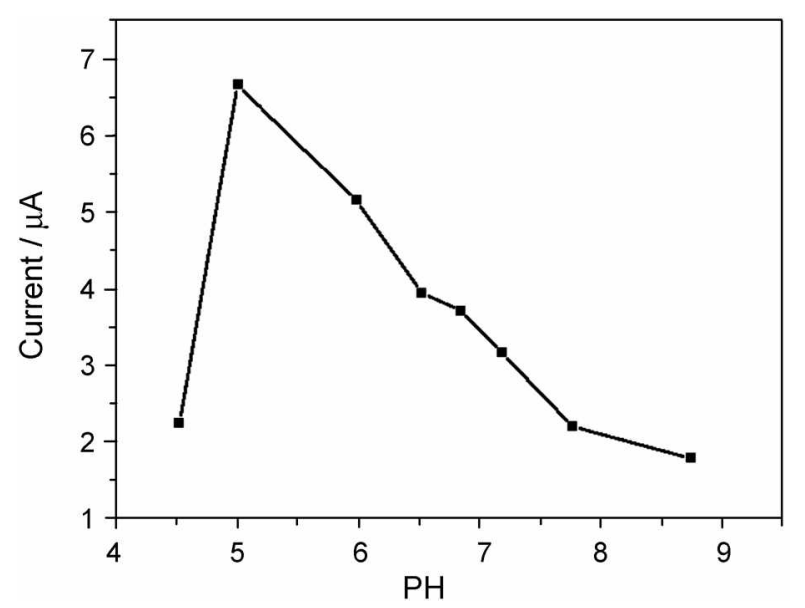

Figure 8. Dependence of the oxidation peak current of $1.0 \times 10^{-5}$ mol $\mathrm{L}^{-1}$ acetaminophen on the $\mathrm{pH}$ value. Supporting electrolyte: $1 / 15 \mathrm{~mol} \mathrm{~L}^{-1}$ phosphate buffer.

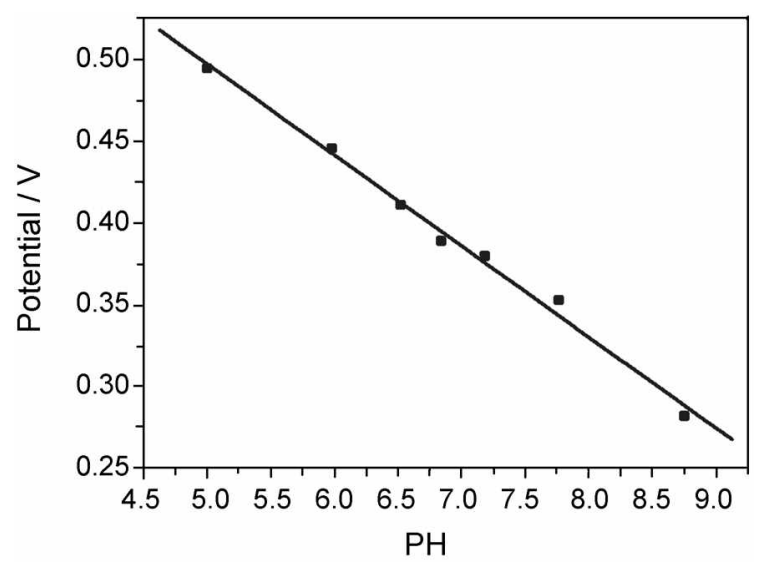

Figure 9. Effects of $\mathrm{pH}$ value on the oxidation peak potential. Conditions as Fig. 8.

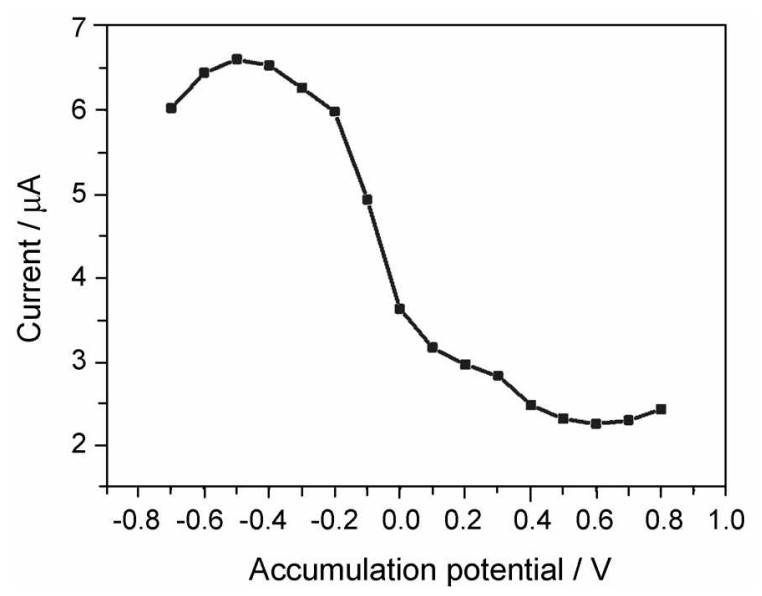

Figure 10. Influence of accumulation potential on the oxidation peak current of $1.0 \times 10^{-5}$ mol L $\mathrm{L}^{-1}$ acetaminophen in phosphate buffer ( $\mathrm{pH} 5.0$ ). Accumulation time: $80 \mathrm{~s}$.

$\mathrm{pH}$ value $(5.0)$ was adopted in the following experiment. Figure 9 displayed the dependence of the oxidation peak potential (Epa) on the $\mathrm{pH}$ value. It was found that Epa shifted less positively with the increase of $\mathrm{pH}$ from 4.5 to

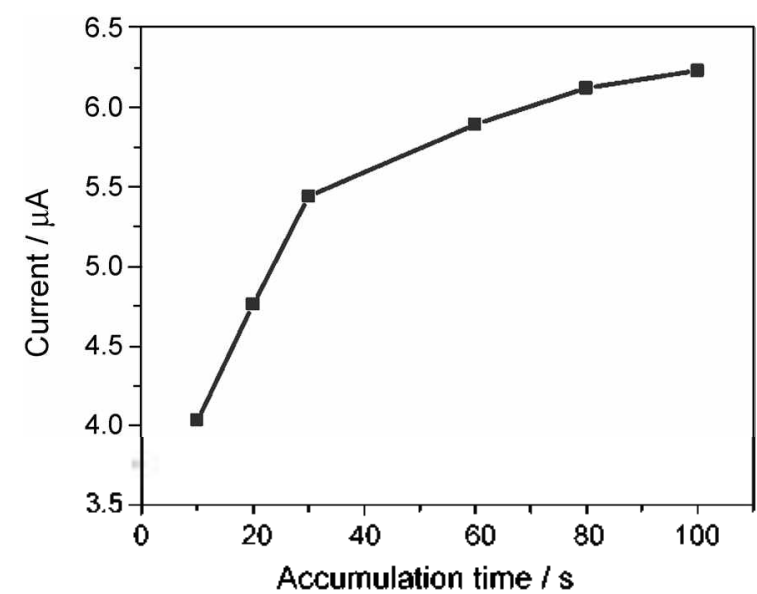

Figure 11. Influence of accumulation time on the oxidation peak current of $1.0 \times 10^{-5}$ mol L-1 acetaminophen in phosphate buffer ( $\mathrm{pH} 5.0$ ). Accumulation potential: $-0.50 \mathrm{~V}$.

8.8. A linear relationship can be obtained with following equation: $\mathrm{Ep}=-0.0557 \mathrm{pH}+0.776, \mathrm{r}=0.996$. A slope of $0.0557 \mathrm{~V}$ per $\mathrm{pH}$ unit, from which $\mathrm{m} / \mathrm{n}$ value of 1 is estimated, suggested that the proton-transfer number $(\mathrm{m})$ is equal to the electron-transfer number (n).

Accumulation conditions. Accumulation conditions including accumulation potential and accumulation time can affect the amount of acetaminophen adsorbed on the composite film electrode surface so as to improve the determination sensitivity. The influence of accumulation potential on the oxidation peak current of $1.0 \times 10^{-5} \mathrm{~mol} \mathrm{~L}^{-1}$ acetaminophen was examined after $80 \mathrm{~s}$ accumulation under potential range from $-0.70 \mathrm{~V}$ to $0.80 \mathrm{~V}$. As shown in Figure 10, in the potential range from $-0.80 \mathrm{~V}$ to $-0.5 \mathrm{~V}$, the oxidation peak current increased slightly. Then, it decreased when further increase in the accumulation potential and a maximum value was obtained at $-0.50 \mathrm{~V}$. Thus the accumulation potential, $-0.50 \mathrm{~V}$, was employed in the subsequent measurements.

From the plot of the oxidation peak current and the accumulation time, Figure 11, we can see that accumulation time also has great effects on the current response of acetaminophen at the MWNT/DHP/PEG composite film electrode. The peak current increased greatly in the first $80 \mathrm{~s}$ due to the more adsorption. When the accumulation was longer than $80 \mathrm{~s}$, it remained almost unchanged because of the saturate adsorption.

Calibration and interferences. Under optimized experimental conditions, the calibration curve for the determination of acetaminophen was examined by linear sweep voltammetry. The plot of the peak current and acetaminophen concentration was shown in Figure 12. An excellent linearity was observed over a wide concentration range from $5.0 \times 10^{-7} \mathrm{~mol} \mathrm{~L}^{-1}$ to $1.0 \times 10^{-4} \mathrm{~mol} \mathrm{~L}^{-1}$ with a correlation coefficient of 0.996 . The linear regression equation can be expressed as following:

Ip $(\mu \mathrm{A})=0.393 \mathrm{C}+1.592$, where $\mathrm{C}$ is in $\mu \mathrm{mol} \mathrm{L} \mathrm{L}^{-1}$.

Experimental results showed that the detection limit was 


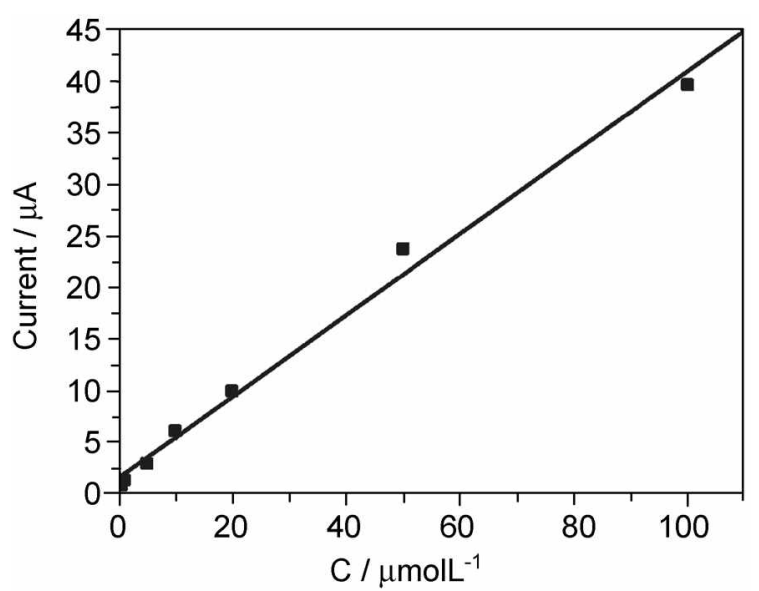

Figure 12. Calibration curve for the determination of acetaminophen at the composite film electrode.

$5.0 \times 10^{-8} \mathrm{~mol} \mathrm{~L}^{-1}(\mathrm{~S} / \mathrm{N}=3)$. A relative standard deviation of $2.8 \%$ for $1.0 \times 10^{-5} \mathrm{~mol} \mathrm{~L}^{-1}$ acetaminophen $(\mathrm{n}=6)$ suggested that the composite film electrode process good reproducibility. Six composite film electrodes fabricated independently were used to determine $1.0 \times 10^{-5} \mathrm{~mol} \mathrm{~L}^{-1}$ acetaminophen, and the relative standard deviation is $3.5 \%$, revealing an excellent repeatability of the electrode preparation. The stability of the film electrode was evaluated by measuring the peak current of $1.0 \times 10^{-5} \mathrm{~mol} \mathrm{~L}^{-1}$ acetaminophen repeatedly. After 50-times determination, the peak current deviated from its original response only $4.7 \%$, revealing that the fabricated MWNT/DHP/PEG film electrode processes long-term stability.

In order to evaluate the specificity of the film electrode in the determination of acetaminophen, some possible interfering substances was added to $1.0 \times 10^{-6} \mathrm{~mol} \mathrm{~L}^{-1}$ acetaminophen and the oxidation peak current was measured. There was no substantial change in the current response in the presence of less than 10-fold concentration of glucose, ascorbic acid, uric acid and L-cysteine. 50-fold concentration of $\mathrm{Zn}^{2+}, \mathrm{Fe}^{3+}, \mathrm{Ni}^{2+}$, and $\mathrm{Al}^{3+}$ did not interfere with the current response of acetaminophen (signal change below $5.0 \%$ ), meanwhile, 50 -fold concentration of $\mathrm{Co}^{2+}$ cause the response of acetaminophen decrease greatly. However, 5fold concentration of ethinylestradiol, dopamine and hymecromon can cause enhancement in the peak current, due to have similar structures for their hydroxyl groups and may be oxidized near the oxidation potential of acetaminophen at the film electrode.

Determination of acetaminophen in the pharmaceutical samples. The MWNT/DHP/PEG film electrode was employed to determine the content of acetaminophen in Children's Bufferin Paracetamol Oral Solution (Shanghai Shiguibao Pharm. Co., China). The oral solution was diluted with phosphate buffer $(\mathrm{pH} 5.0)$ at the ratio of $1: 100$. After that, $10 \mu \mathrm{L}$ of the diluted sample solution was added into an electrochemical cell containing $10 \mathrm{~mL}$ phosphate buffer, and the voltammograms were recorded as the mentioned procedure. The concentration of acetaminophen in the voltametric cell calculated from the regression equation was $5.18 \times 10^{-6}$ $\mathrm{mol} \mathrm{L}^{-1}(\mathrm{n}=3)$, therefore, the content of acetaminophen in the oral solution was $31.39 \mathrm{mg} \mathrm{mL}^{-1}$ which was consistent well with that the certified value $\left(32.00 \mathrm{mg} \mathrm{mL}^{-1}\right)$ of the analyte. UV spectroscopy was applied to evaluate the veracity of the proposed electrochemical method, and a standard curve method was developed for the determination of acetaminophen in the concentration range from $5.0 \times 10^{-7}$ mol L $\mathrm{L}^{-1}$ to $5.0 \times 10^{-5} \mathrm{~mol} \mathrm{~L}^{-1}$. The calculated content of acetaminophen in the oral solution was $31.51 \mathrm{mg} \mathrm{mL}^{-1}$. The results suggested that the MWNT/DHP/PEG composite film electrode was very reliable, selective and sensitive enough for the determination of acetaminophen in real pharmaceutic samples.

\section{Conclusions}

In this work, a MWNT/DHP/PEG composite film modified glassy carbon electrode was fabricated easily for the electrochemical investigation of acetaminophen by cyclic voltammetry, linear sweep voltammetry and chronocoulometry. It was found that the peak current response of acetaminophen was improved significantly and the oxidation peak shifted towards negative potential in the presence of MWNT/DHP/PEG composite film. The results indicated that the composite film provided a good platform to accumulate acetaminophen. The enhanced accumulation of acetaminophen mainly came from the unusual properties of carbon nano-tubes such as strong adsorptive ability, huge specific area. As a result, the film electrode was successfully employed for the voltammetric determination of acetaminophen. Its advantages, such as simple, sensitive, rapid and accurate, were demonstrated by the determination of acetaminophen in the pharmaceutical samples with good result.

\section{References}

I. Miller, J.; Hickman, R.; Fratter, R.; Terblanche, J.; Saunders, S. J. Gastroenterology 1976, 71, 109.

2. Olivac, M. A.; Olsinaa, R. A.; Masib, A. N. 7alanta 2005, 66, 229.

3. Vale, J. A.; Proudfoot, A. T. Lancet 1995, 346, 547.

4. Srivastava, M. K.; Ahmed, S.; Singh, D.; Shukla, I. C. Analyst $1985,110,735$.

5. Filik, H.; Hayvali, M.; Kilic, E. Anal. Chim. Acta 2005, 535, 177.

6. Dinc, E.; Yucesoy, C.; Onur, F. J. Pharm. Bionted. Anal. 2002, 28 , 1091 .

7. Bouhsain, Z.; Garrigues, S.; Rubio, A. M.; Guardia, M. Anal. Chim. Acta 1996, 330, 59.

8. Criado, A.; Cardenas, S.; Gallego, M.; Valcarcel, M. Takanta $2000,53,417$.

9. Canada, M. J. A.; Reguera, M. I. P.; Medina, A. R.; Cordova, M. L. F.; Diaz, A. M. J. Pharm. Bioned. Anal, 2000, 22, 59.

10. Staden, J. F. V.; Tsanwani, M. Tolanta 2002, 58, 1005.

11. Moreira, A. B.; Oliveira, H. P. M.; Atvars, T. D. Z.; Dias, I. L. T.; Neto, G. O.; Zagatto, E. A. G.; Kubota, L. T. Anal. Chim. Acta $2005,539,257$.

12. Giorgio, G.; Erika Del, G; Roberta, R.; Gianna, A. J. Pharm. Biomed, Anal. 2006, 4I, 798 .

13. Dinc, E.; Ozdemir, A,; Aksoy, H.; Balearm, D. J. Liq. Chromatogr. Rel. Techn. 2006, 29, 1803. 
14. Zhao, S. L.; Bai, W. L.; Yuan, H. Y; Xiao, D. Antal. Chim. Acta $2006,559,195$.

15. Perez-Ruiz, T.; Martinez-Lozano, C.; Tomas, V.; Galera, R. J. Pham. Bioned. Anal. 2005, 38,87.

16. Pedrosa, V. A.; Lowinsohn, D.; Bertotii, M. Electroanal. 2006, 18 , $93 \mathrm{l}$.

17. Van Staden, J. F.; Tsanwani, M. Takanta 2002, 58, 1095.

18. Bi, S.; Wang. G.; Piao, Y.; Wang, D.; Yin, X. Yanbian Daxue Xitebao (Ziran Kextreban) 2000,26, 110.

19. Goyal, R. N.; Singh, S. P. Electrochim, Acta 2006, 51, 3008.

20. Wangfuengkanagul, N.; Chailapakul, O.J. Pharm. Bioned. Anal.
2002, 28, 841.

21. Rajendra, N. G.; Vinod, K. G.; Munetaka, O.; Neeta, B. Electrochen. Conmitm. 2005, 7, 803.

22. Mannan, B.; Won, M.-S.; Shim, Y.-B. Anal. Chim. Acta 2004, $5 / 2,191$.

23. Anson, F. C. Anal. Chem. 1964, 36, 932.

24. Martinhon, P. T.; Carreno, J.; Sousa, C. R.; Barcia, O. E.; Mattos, O. R. Electrochim. Acta 2006, $5,3022$.

25. Hu, C. G.; Yuan, S.; Hu, S. S. Electrochim. Acta 2006, 51, 3013.

26. Ni, Y. N.; Wang, Y. R.; Kokot, S. Anal. Lett. 2004, 37, 3219. 